\title{
Towards more implications of biochemistry in neuroscience
}

Volume 2 Issue 4 - 2015

\section{Editorial}

Neuroscience is among the most important modern sciences and that includes a variety of fields such as cognitive neuroscience ${ }^{1,2}$ and educational neuroscience. ${ }^{3}$ The main focus of neuroscience is the physiology and the pathology of the nervous system at molecular, cellular and organizational levels

The nervous system represents a network within which a huge amount of signals are transmitted via neurons thorough a variety of neurotransmitters ${ }^{4,5}$ and gap junctions. Many phenomena related to the nervous system remain unexplained ${ }^{6}$ and among those explained, the explanations are still theories yet to become facts. May be it is necessary to go beyond the neurotransmitters mechanisms, cognition and psychology; and further investigate the "non-neurological" aspects of the nervous system to further understand the panoramic image of this mysterious yet amazing system.

Indeed, biochemistry, as a science that defines the chemistry of life, provides key features to elucidate the functions of enzymes, biomolecules, and ions. These elements play important role in the physiology and the biology of the nervous system and the neurons; including energy transfer, neurotransmitters synthesis and degradation, cell death and membranes potential. In addition biochemistry can explain the effects chemical can have on neurons too. ${ }^{7}$ Importantly, biochemistry also describes metabotropic receptors of the nervous system, such as the $\mathrm{G}$ protein coupled receptors, ${ }^{8}$ that play important roles in both neurophysiology ${ }^{9}$ and neuropharmacology. ${ }^{10}$ Furthermore, biochemistry governs biological events related to field such as genetic (gene expression) and proteomics that are closely related to the wellfunctioning of the nervous system as well.

Such concepts, if put within the adequate context, would surely strengthen our knowledge about neuroscience and provide fruitful details to understand neurological functioning, develop therapies (based on both biochemistry and pharmacology ${ }^{11-13}$ ), build animal models of neurological disease ${ }^{14,15}$ such as Alzheimer's disease ${ }^{16,18}$ and Parkinson disease. ${ }^{19}$

\section{Acknowledgements}

Abdelaziz Ghanemi is a recipient of a 2013 CAS-TWAS President's Postgraduate Fellowship.

\section{Conflicts of interest}

None.

\section{References}

1. McClelland JL, Ralph MAL. Cognitive Neuroscience. In: Wright JD (Ed.), International Encyclopedia of the Social \& Behavioral Sciences. ( $2^{\text {nd }}$ edn), Elsevier, Oxford. 2015;pp.95-102.

2. Frank MJ, Badre D. How cognitive theory guides neuroscience. Cognition. 2015;135:14-20.

\author{
Abdelaziz Ghanemi, $1,2,3$ \\ 'Key Laboratory of Animal Models and Human Disease \\ Mechanisms of the Chinese Academy of Sciences \& Yunnan \\ Province, Kunming Institute of Zoology, Chinese Academy of \\ Sciences , Kunming, Yunnan 650223, PR China \\ ${ }^{2}$ Kunming College of Life Science, University of Chinese \\ Academy of Sciences, Kunming 650204, China \\ ${ }^{3}$ University of Chinese Academy of Sciences, Beijing, China
}

Correspondence: Abdelaziz Ghanemi, Key Laboratory of Animal Models and Human Disease Mechanisms, Kunming Institute of Zoology Chinese Academy of Sciences, No. 32 Jiao chang dong lu, Kunming 65223, China, Email ghanemiabdelaziz@hotmail.com

Received: July 09, 2015 | Published: July 10, 2015

3. Tolmie A. Neuroscience of Education, In: Wright JD (Ed.), International Encyclopedia of the Social \& Behavioral Sciences. (2 ${ }^{\text {nd }}$ edn), Elsevier, Oxford. 2015;pp.728-735.

4. Ghanemi A. Psychiatric neural networks and neuropharmacology: Selected advances and novel implications. Saudi Pharm J. 2014;22(2):95-100.

5. Ghanemi A. Schizophrenia and Parkinson's disease: Selected therapeutic advances beyond the dopaminergic etiologies. Alexandria Journal of Medicine. 2013;49(4):287-291.

6. Adolphs R. The unsolved problems of neuroscience. Trends Cogn Sci. 2015;19(4):173-175.

7. Ghanemi A. Biological properties and perspective applications of "Bioneuter" chemicals? Saudi Pharm J. 2014;22(1):1-2.

8. Ghanemi A, He L, Yan M. New factors influencing G protein coupled receptors' system functions. Alexandria Journal of Medicine. 2013;49(1):1-5.

9. Ghanemi A, Hu X. Elements toward novel therapeutic targeting of the adrenergic system. Neuropeptides. 2015;49:25-35.

10. Ghanemi A. Targeting G protein coupled receptor-related pathways as emerging molecular therapies. Saudi Pharm J. 2015;23(2):115-129.

11. Ghanemi A. How to define a pharmacological or a toxic food? Alexandria Journal of Medicine. [Article In Press]. 2014.

12. Ghanemi A, Boubertakh B. Shorter and sturdier bridges between traditional Chinese medicines and modern pharmacology. Saudi Pharm J. 2015;23(3):330-332.

13. Ghanemi A. Is mapping borders between pharmacology and toxicology a necessity? Saudi Pharm J. 2014;22(6):489-490.

14. Ghanemi A. How to map the bridges between zoology and pharmacology? The Journal of Basic \& Applied Zoology. [Article in Press]. 2015.

15. Giusto E, Donega M, Cossetti C, et al. Neuro-immune interactions of neural stem cell transplants: From animal disease models to human trials. Exp Neurol. 2014;260:19-32. 
16. Ghanemi A. Animal models of Alzheimer's disease: Limits and challenges. NPG Neurologie-Psychiatrie-Geriatrie. 2014;14(84):303305 .

17. Ghanemi A. Alzheimer's disease therapies: Selected advances and future perspectives. Alexandria Journal of Medicine. 2015;51(1):1-3.
18. Chen $\mathrm{X}$, Hu J, Jiang L, et al. Brilliant Blue G improves cognition in an animal model of Alzheimer's disease and inhibits amyloid- $\beta$ induced loss of filopodia and dendrite spines in hippocampal neurons. Neuroscience. 2014;279:94-101.

19. Morin N, Jourdain VA, Di Paolo T. Modeling dyskinesia in animal models of Parkinson disease. Exp Neurol. 2014;256:105-116. 